\title{
Correction to: Tightening methods based on nontrivial bounds on bilinear terms
}

\author{
Yifu Chen ${ }^{1} \cdot$ Christos T. Maravelias $^{2}$
}

Published online: 7 November 2021

(c) Springer Science+Business Media, LLC, part of Springer Nature 2021

\section{Correction to: Optimization and Engineering https://doi.org/10.1007/s11081-021-09646-8}

In the original publication of the article, the funding grant number was published incorrectly. The corrected number is given below.

Acknowledgements The authors acknowledge financial support from the National Science Foundation under grant CBET-2026980.

Publisher's Note Springer Nature remains neutral with regard to jurisdictional claims in published maps and institutional affiliations.

The original article can be found online at https://doi.org/10.1007/s11081-021-09646-8.

Christos T. Maravelias

maravelias@princeton.edu

1 Department of Chemical and Biological Engineering, University of Wisconsin-Madison, 1415 Engineering Dr, Madison, WI 53706, USA

2 Department of Chemical \& Biological Engineering and Andlinger Center for Energy and the Environment, Princeton University, 86 Olden Street, Princeton, NJ 08544, USA 